\title{
Response of the equatorial and low-latitude ionosphere during the space weather events of April 2002
}

\author{
W. L. C. Lima ${ }^{1}$, F. Becker-Guedes ${ }^{2}$, Y. Sahai ${ }^{2}$, P. R. Fagundes ${ }^{2}$, J. R. Abalde ${ }^{2}$, G. Crowley ${ }^{3}$, and J. A. Bittencourt ${ }^{4}$ \\ ${ }^{1}$ Centro Univ. Luterano de Palmas (CEULP), Universidade Luterana do Brasil (ULBRA), 77054-970 Palmas, TO, Brazil \\ ${ }^{2}$ Universidade do Vale do Paraíba (UNIVAP), 12244-000 São José dos Campos, SP, Brazil \\ ${ }^{3}$ Southwest Research Institute, San Antonio, TX 78238-5166, USA \\ ${ }^{4}$ Instituto Nacional de Pesquisas Espaciais (INPE), 12201-970 São José dos Campos, SP, Brazil
}

Received: 13 August 2003 - Revised: 31 May 2004 - Accepted: 11 June 2004 - Published: 23 September 2004

Part of Special Issue "Equatorial and low latitude aeronomy"

\begin{abstract}
A digital ionosonde, of the type known as Canadian Advanced Digital Ionosonde (CADI), has been in routine operation at São José dos Campos $\left(23.2^{\circ} \mathrm{S}, 45.9^{\circ} \mathrm{W}\right.$; dip latitude $17.6^{\circ} \mathrm{S}$ ), Brazil, since August 2000. A new CADI was installed at Palmas $\left(10.2^{\circ} \mathrm{S}, 48.2^{\circ} \mathrm{W}\right.$; dip latitude 5.5 $\left.{ }^{\circ} \mathrm{S}\right)$, Brazil, in April 2002. The two CADIs are part of a new network being established in a collaborative program between UNIVAP and CEULP/ULBRA, to study the equatorial and low-latitude ionospheric regions in Brazil. In this paper we present and discuss the effects of the space weather events during 17-20 April 2002, as evidenced by the ionospheric parameter changes from simultaneous observations at São José dos Campos and Palmas. A comparison of the observed ionospheric parameters $\left(h^{\prime} F, h p F 2\right.$ and $\left.f o F 2\right)$ at the two stations, separated only by about $1460 \mathrm{~km}$, shows both similarities and differences associated with the geomagnetic disturbances. Also, a comparison of the observed $F$-region parameters with the ASPEN-TIMEGCM model results is presented. The model results show reasonable agreement during the quiet period of observations, but some discrepancies have been observed during the geomagnetic disturbances.
\end{abstract}

Key words. Ionosphere (ionospheric disturbances; modeling and forecasting); magnetospheric physics (storms and substorms)

\section{Introduction}

The studies related to space weather events are becoming increasingly important in the Sun-Earth system. As pointed out by Schunk and Sojka (1996), space weather disturbances in the ionosphere-thermosphere system can have detrimental effects on both ground-based and space-based systems. Dur-

Correspondence to: W. L. C. Lima

(wlima@ulbra-to.br) ing the recent past, the response of the equatorial ionosphere to intense/major geomagnetic (ionospheric) storms has been the subject of several investigations (e.g. Sridharan et al., 1999; Basu et al., 2001; Basu, Su. et al., 2001; Lee et al., 2002; Lee, J. J. et al., 2002; Sastri et al., 2002). During geomagnetic storms, which are extreme forms of space weather disturbances, the electric fields in the equatorial ionosphere could be primarily affected by two processes: 1) the solar wind-magnetosphere dynamo, associated with prompt or direct penetration of the magnetospheric convective electric field (e.g. Senior and Blanc, 1984; Spiro et al., 1988) and 2) the ionospheric disturbance dynamo, due to global thermospheric wind circulation associated with Joule heating at high latitude (e.g. Blanc and Richmond, 1980). Recently, Scherliess and Fejer (1997) and Fejer and Scherliess (1997) have discussed in detail the storm time dependence of the equatorial zonal electric fields.

In the month of April 2002, during the transit of the active region 9906 on the solar disk, three eruptions took place in a quick succession. The first two solar eruptions launched fast coronal mass ejection (CME) directed towards the Earth, triggering double-peaked moderate/intense geomagnetic storms on 17 and 19 April. The first peak, in each case, is due to the impact of the shock/sheath preceding the CME and the second peak is due to the passage of the CME itself (Dr. Janet Kozyra, personal communication, 2003), whereas the third eruption (21 April) was not directed at the Earth. Because of the recurring space weather events during a short spell, the period 14-24 April 2002, attracted much attention and the period was selected for special studies (see workshop details on the website: http://storms.jhuapl.edu/20020807/index.html; also, a special session on "Tracing the Sun-Earth Connection into the Upper Atmosphere: Study of the 14-24 April 2002 Events" was organized at the Fall 2002 AGU meeting). 


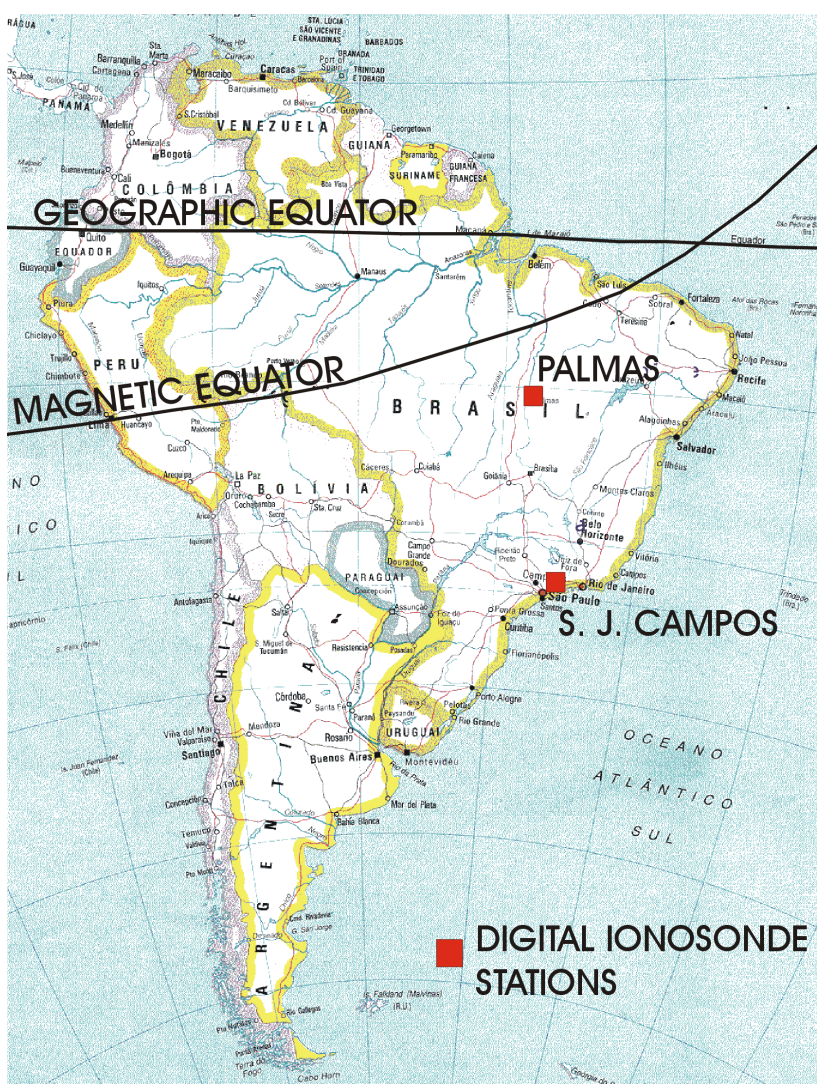

Fig. 1. Map of South America showing the locations of the ionospheric sounding stations and of the geographic and magnetic equators.

Incidentally, a new ionospheric sounding station equipped with a Canadian Advanced Digital Ionosonde (CADI) (Grant et al., 1995) was put in operation at Palmas $\left(10.2^{\circ} \mathrm{S}, 48.2^{\circ} \mathrm{W}\right.$; dip latitude $5.5^{\circ} \mathrm{S}$ ), in the equatorial region in Brazil, on 14 April 2002. Another ionospheric sounding station with a CADI was in routine operation at São José dos Campos $\left(23.2^{\circ} \mathrm{S}, 45.9^{\circ} \mathrm{W}\right.$; dip latitude $\left.17.6^{\circ} \mathrm{S}\right)$, a low-latitude station in Brazil, since August 2000. In this paper we present the simultaneous ionospheric sounding observations carried out at Palmas and São José dos Campos, to investigate the response of the equatorial and low-latitude ionospheric regions during the space weather events which occurred in the period 16-20 April 2002. Also, the $F$-region parameters, obtained for the two ionospheric sounding stations, are compared with the model results (hourly values) generated by the Advanced SPace ENvironment (ASPEN)-Thermosphere Ionosphere Mesosphere Electrodynamics General Circulation Model (TIMEGCM) (Crowley et al., 1999; see also Roble and Ridley, 1994), for the period 16-20 April 2002.

\section{Observations}

Figure 1 shows the locations of the ionospheric sounding stations. These two stations are separated only by about
$1460 \mathrm{~km}$, one located close to the magnetic equator (PAL) and the other one close to the peak in the equatorial ionospheric anomaly region (SJC), having fairly close magnetic meridians and in the same local time zone. For both the sounding stations, we have UT=LT $+3 \mathrm{~h}$. Two $F$-region parameters, the minimum virtual height of the $F$-layer $\left(h^{\prime} F\right)$ and critical frequency $f o F 2$, for the period 16-20 April, 2002 (16, quiet, and 17-20, disturbed), were obtained every 5 min at Palmas (hereafter referred as PAL) and São José dos Campos (hereafter referred as SJC). To determine the height of the maximum density of the $F$-region, we have used $h p F 2$ (the virtual heights at $0.834 f o F 2$ ) in this investigation. The values of $h p F 2$ were obtained every $30 \mathrm{~min}$ from observations at PAL and SJC. It should be pointed out that considering a single parabolic layer with no underlying ionization $h p F 2$ is equal to the actual height of the maximum of $F$ region (World Data Center A report UAG-23, 1972). Also, Danilov and Morozova (1985) have pointed out that the determination of the peak $F$-layer height $(h m F 2)$ using $h p F 2$ is less reliable during the daytime (the altitude $h p$ is overestimated with respect to the true altitude of the maximum of the layer $h m F 2$ ) than at nightime where $h p F 2 \approx h m F 2$. However, in the present investigation, the main interest is related to the large height changes during the disturbed conditions and therefore, the use of $h p F 2$ even during the daytime appears to be reasonable. The quiet time average diurnal patterns of $h^{\prime} F, h p F 2$ and $f o F 2$ presented in this study were obtained for each station from the quiet day observations (every $30 \mathrm{~min}$ ) on 15, 16, 21, 22, 25, 26, 29, and 30 April 2002.

Figure 2 shows the variations in $K_{p}$ (intensity of storms; 3-hourly values), $D_{s t}$ (intensity of the ring current; hourly values) and $\mathrm{AE}$ (intensity of the auroral electrojet; every 1-min values) geomagnetic indices during the period 1620 April, revealing complex and intense geomagnetic field variations. The $K_{p}$ index reveals two double-peaked geomagnetic storms, as characterized in Table 1. Also, the first double-peaked storm did not recover before the second double-peaked storm was triggered. During the period studied, we had 4 storm-time sudden commencements (SSCs), occurring at 20:11 UT (17:11 LT) on 16 April, 11:07 UT (08:07 LT) on 17 April, 00:32 UT (21:32 LT on 17 April) on 18 April, and 08:35 UT (05:35 LT) on 19 April. The magnetic field ( $H$-component) variations, shown in Fig. 2 , were obtained at the Magnetic Observatory of Vassouras $\left(22.4^{\circ} \mathrm{S}\right.$, $34.6^{\circ} \mathrm{W}$; dip latitude $18.5^{\circ} \mathrm{S}$ ), Brazil, located close to the ionospheric sounding stations. The $H$-component variations (every minute), for the period 16-20 April, shown in Fig. 2, were obtained after subtracting the quiet day (16 April) $\mathrm{H}$ component diurnal variations and represent the storm-time $H$-component variations. The interplanetary magnetic field (IMF) $\mathrm{B}_{z}$ component variations, shown in Fig. 2, are 5-min average values obtained from the website: http://www.srl. caltech.edu/ACE/ASC/. 

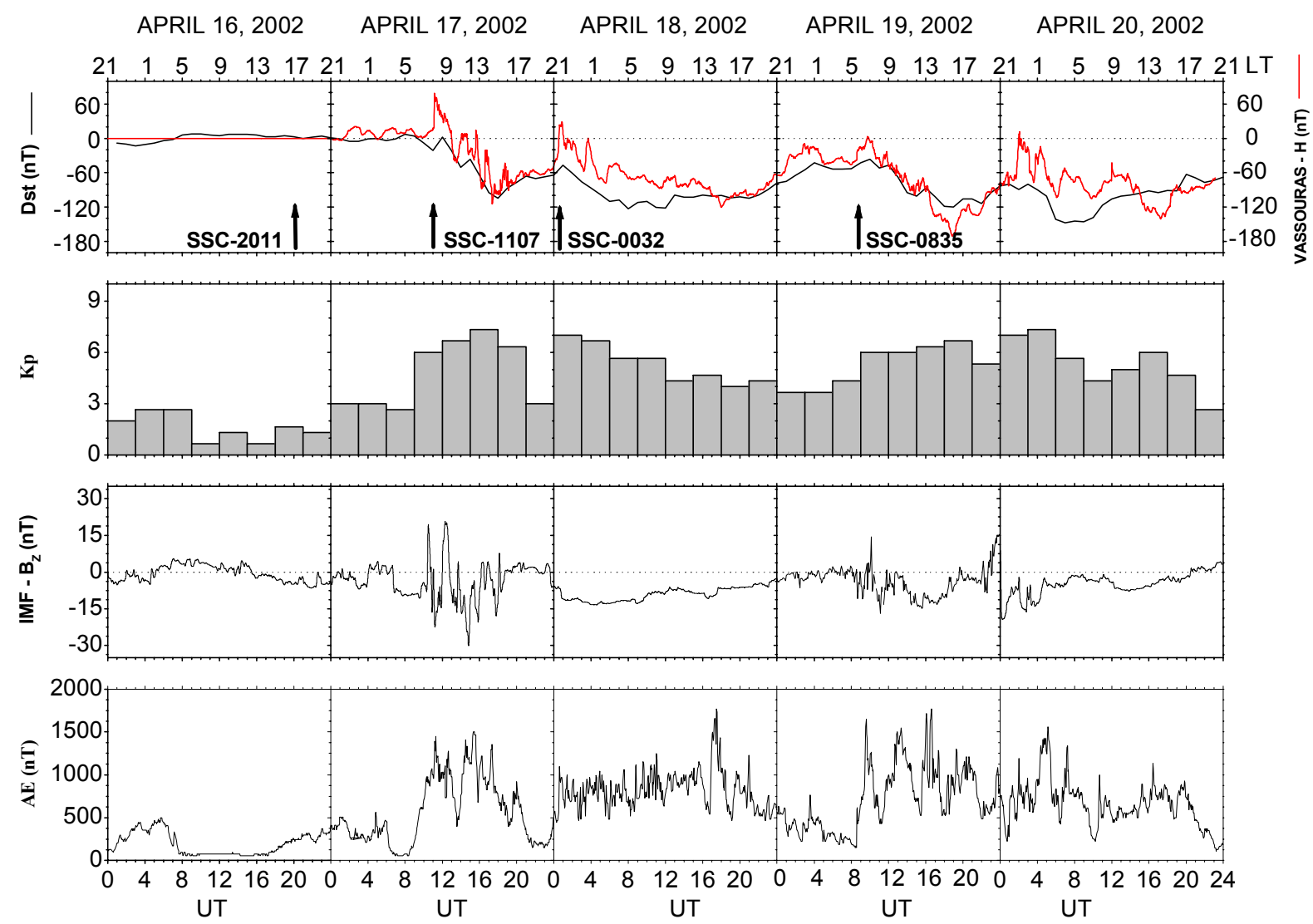

Fig. 2. The variations of the $K_{p}, D_{s t}$, AE geomagnetic indices and of the IMF $B_{z}$ component, during the period 16-20 April 2002. Also, the geomagnetic $H$-component variations observed during the period 16-20 April 2002 at Vassouras, Brazil, are shown with the $D_{s t}$ index variations.

Table 1. Details of geomagnetic activity during the period 17-20 April 2002

\begin{tabular}{lllll}
\hline Events & First Peak & & Second Peak \\
& $K_{p \max }$ & $D_{s t \max }$ & $K_{p \max }$ & $D_{s t \max }$ \\
\hline First double- & $7+$ & $106 \mathrm{nT}$ & 7 & $126 \mathrm{nT}$ \\
peaked storm & 15:00-18:00 UT & $18: 00 \mathrm{UT}$ & $00: 00-03: 00 \mathrm{UT}$ & $08: 00 \mathrm{UT}$ \\
17-18 April & 17 April & 17 April & 18 April & 18 April \\
Second double- & $7-$ & $122 \mathrm{nT}$ & $7+$ & $151 \mathrm{nT}$ \\
peaked storm & 18:00-21:00 UT & 19:00 UT & 03:00-06:00 UT & 07:00 UT \\
19-20 April & 19 April & 19 April & 20 April & 20 April \\
\hline
\end{tabular}

\section{Results and discussions}

Figures 3 and 4 show the variations of $h^{\prime} F$ (black line), $h p F 2$ (black line) and $f o F 2$ (black line) during the storm period observed at PAL and SJC, respectively. The average quiet condition diurnal variations of $h^{\prime} F, h p F 2$ and $f o F 2$ are shown as gray bands, and the width of the gray bands corresponds to \pm 1 standard deviation of the observed parameters. The hatched portions in Figs. 3 and 4 indicate local nighttime (18:00-06:00 LT) periods. The ASPEN-TIMEGCM model results for $h m F 2$ (orange line) and $f o F 2$ (orange line) are shown in Figs. 3 and 4. Also, Figs. 3 and 4 show the average quiet condition diurnal variations of $h m F 2$ (red line with error bars; \pm 1 standard deviation) and $f o F 2$ (red line with error bars; \pm 1 standard deviation) from the TIMEGCM model and were calculated from the quiet day results (every hour) on 14, 15, 16, 21 and 22 April 2002.

Studies related to ionospheric storms have been reviewed by several investigators (e.g. Danilov and Morozova, 1985; Schunk and Sojka, 1996; Abdu, 1997; Buonsanto, 1999). It should be pointed out that the $F$-region height (e.g. $h^{\prime} F$ and $h p F 2$ ) changes during geomagnetic storms are good in- 


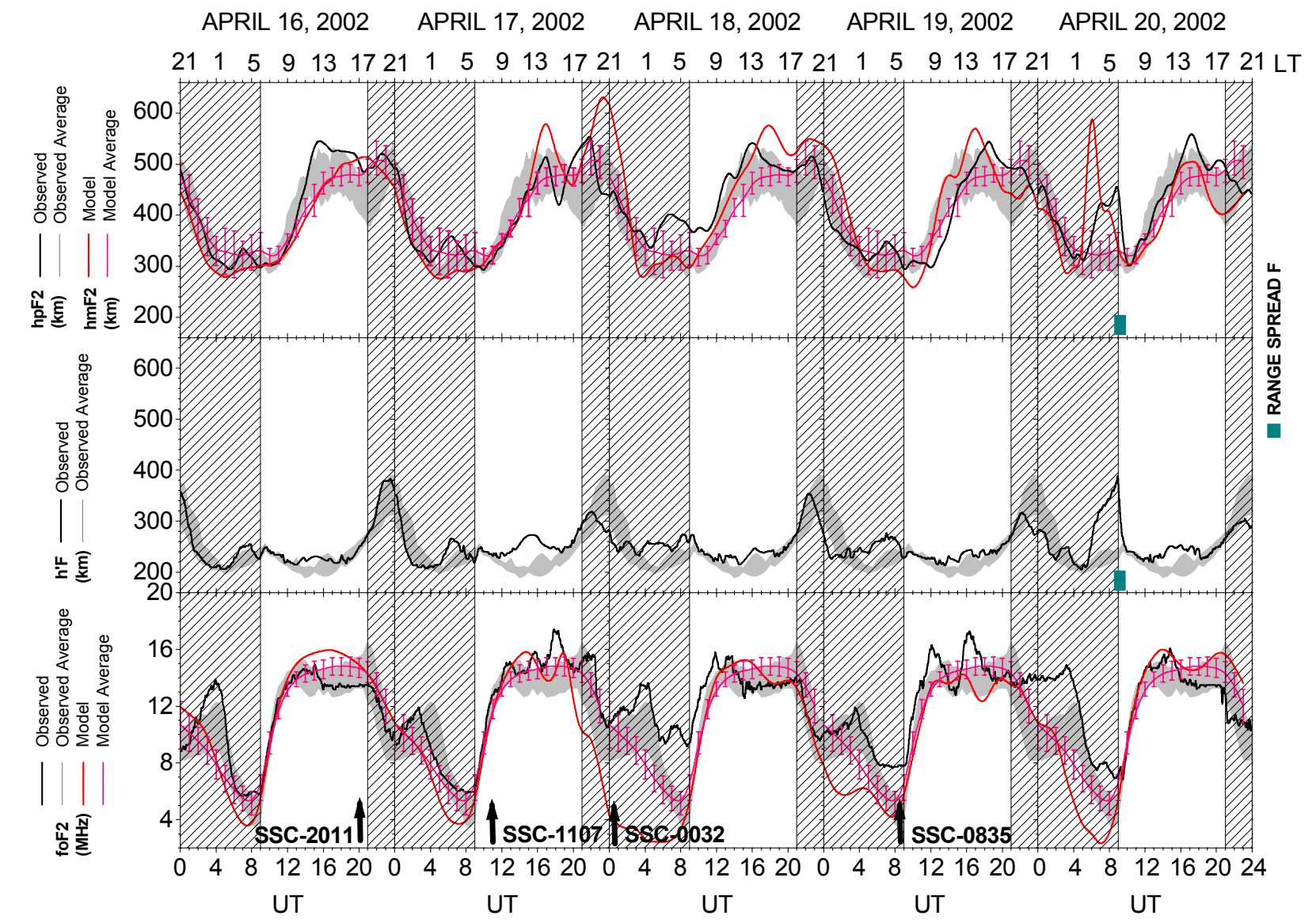

Fig. 3. The variations of $h^{\prime} F$ (black), $f o F 2$ (black) and $h p F 2$ (black) during the period 16-20 April 2002 observed at Palmas (PAL). The average quiet-day variations of $h^{\prime} F, h p F 2$ and $f o F 2$ are shown as gray bands with the band widths indicating \pm 1 standard deviation. The $h m F 2$ (orange) and $f o F 2$ (orange) variations obtained from the ASPEN-TIMEGCM model runs are also shown. The average quiet-day variations of $h m F 2$ and $f o F 2$ from the ASPEN-TIMEGCM model are shown in red color with error bars ( \pm 1 standard deviation). The hatched portions indicate local nighttime periods (18:00-06:00 LT).

dicators of vertical electromagnetic drifts (e.g. Sastri et al., 2002). Also, deviations of $f o F 2$ from the quiet time average values $(\triangle f o F 2>0$ indicates positive ionospheric storm or phase; and $\triangle f o F 2<0$ indicates negative ionospheric storm or phase) are important diagnostics during geomagnetic storms (e.g. Danilov and Morozova, 1985; Schunk and Sojka, 1996) . As pointed out by Sastri et al. (2002), at and close to the magnetic equator, vertical plasma drift is essentially due to zonal electric fields, whereas meridional winds gain in importance with the increase of dip angle (I), with a maximum effect at $\mathrm{I}=45^{\circ}$.

The $h^{\prime} F, h p F 2$ and $f o F 2$ values (Figs. 3 and 4), observed on 16 April and up to about 12:00 UT on 17 April, are very similar to the quiet-day average values, indicating the existence of relatively quiet geomagnetic conditions. However, about one hour after the second SSC (11:07 on 17 April), the ionospheric parameters $h^{\prime} F, h p F 2$ and $f o F 2$, observed at PAL and SJC, start exhibiting deviations from the quiet-day average patterns, which continue up to 20 April. It should be pointed out that, since we are investigating a short period of a few days (17 to 19 April), with occur- rence of several geomagnetic disturbances (storms and substorms) in rather quick succession, the competing influences of different magnetospheric-ionospheric interaction channels (Danilov and Morozova, 1985; see, also, Sobral et al., 1997) could result in amplification or attenuation of geomagnetic effects.

\subsection{Storm-time $h^{\prime} F$ and $f o F 2$ variations}

The principal features observed during the multiple geomagnetic storm period of 17-20 April (hereafter referred to as "the storm period") are presented and discussed in this section. A perusal of Figs. 3 and 4 indicates that, in general, the variations of $f o F 2$ during the storm period follow closely the quiet-day average (median values) variations at both SJC and PAL, except during some short intervals which show deviations from the median values.

\subsection{Positive phase}

Danilov and Morozova (1985) have pointed out that, at equatorial latitudes, the positive phase may sometimes be ob- 


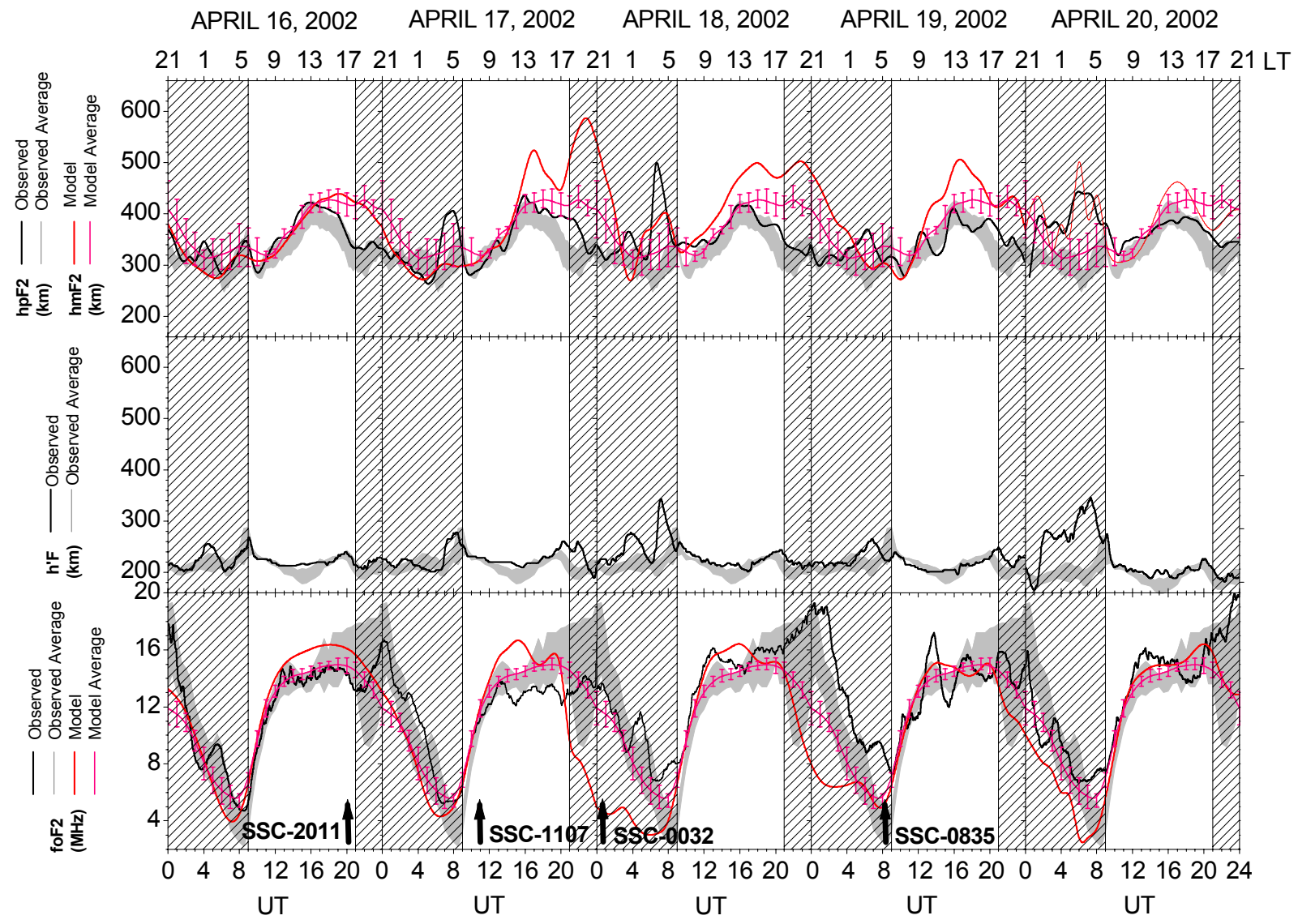

Fig. 4. Same as in Fig. 3, but for São José dos Campos (SJC).

served throughout the entire storm or appreciable changes in $f o F 2$ may not be observed at all. Both stations, PAL and SJC, show positive phase around dawn hours on the period 18, 19 and 20 April. Danilov and Morozova (1985) have indicated that the mechanisms of the formation of the positive and negative phases are linked to different magnetosphereionosphere interaction channels. As pointed out by Prolss and Najita (1975), a possible explanation for positive storm effects at low latitudes is electrodynamic lifting (upward drift of ionization), whereas negative storm effects are almost certainly caused by changes in neutral composition due to atmospheric disturbances originating in the polar zones (increase in recombination rate). A perusal of Figs. 3 and 4 indicates that PAL and SJC show simultaneous uplifting (indicating the penetration of electric field) of the $F$-layer $\left(h^{\prime} f\right.$ and $h p F 2$ ) at the time of the positive phases observed around the dawn hours on 18, 19 and 20 April. In addition to the observed dawn hour positive phases at both PAL and SJC, the variations of $f o F 2$ at SJC show positive phase between about 00:00-08:00 UT on the night of 18-19 April. Also, on 19 April (00:00 UT) and 20 April (23:00 UT), the variations of $f o F 2$ show very high values (close to $20 \mathrm{MHz}$ ). The variations in $f o F 2$ at PAL show positive phase between about 22:00-04:00 UT on the night of 19-20 April. The unusual nighttime enhancements at SJC could be related to the sun- set strengthening of the "fountain process" or they are due to transport of plasma from other regions by meridional winds. The "fountain process" seems unlikely because the presunset behavior of the $F$-region height at PAL does not indicate any unusual enhancement of the zonal electric field and hence the "fountain process". Therefore, the enhancements observed are possibly associated with the transport of plasma from the equatorial region due to the disturbed thermospheric meridional winds. Again, the positive phase on the night of 19-20 April at PAL is accompanied by negative phase at SJC and could be associated with the thermospheric disturbances (equatorward fronts) of the spreading negative phase regions in both hemispheres from higher latitudes (Tanaka, 1979).

\subsection{Wave-like response}

A perusal of Figs. 3 and 4 indicates that after a few hours (2-3 h) from the SSCs on 17 April (11:07 UT) and 19 April (08:35 UT), the variations of $f o F 2$, at both stations, show wave-like disturbances during the daytime, possibly associated with high velocity traveling atmospheric disturbances. Wave-like disturbances at an equatorial station during intense geomagnetic disturbances in the daytime have also been reported by Turunen and Mukunda Rao (1980). The observed wave-like disturbances on 17 and 19 April are possibly asso- 


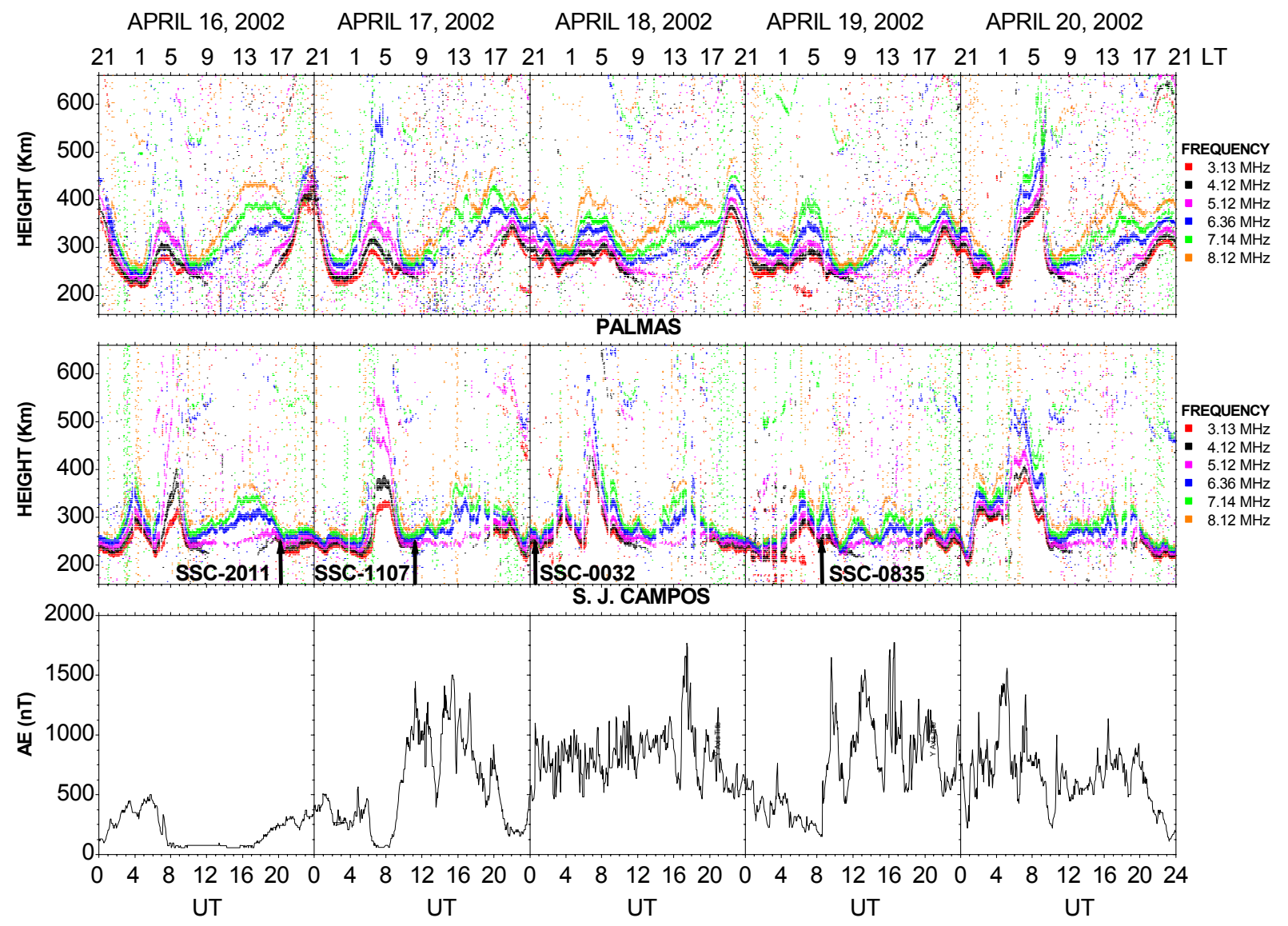

Fig. 5. Virtual height variation plots for different fixed frequencies (iso-frequencies) for the period 16-20 April 2002, observed at PAL (top) and SJC (bottom).

ciated with substorms, indicated by increases in the AE index at 11:15 UT (1400 nT) and 15:30 UT (1500 nT) on 17 April and 09:30 (1600 nT), 13:00 UT (1500 nT) and 16:00 UT (1700 nT) on 19 April, when energy (about $1 \mathrm{~h}$ energy injection representative of a substorm type forcing (Buonsanto, 1999)) is injected in the polar region. As pointed out by numerous authors, this additional energy can launch a traveling atmospheric disturbance (TAD), which propagates with high velocity (Crowley and Williams, 1987; Crowley et al., 1987; Rice et al., 1988; Crowley and McCrea, 1988). Sometimes, TIDs with velocities in excess of $1200 \mathrm{~m} / \mathrm{sec}$ are generated (e.g. Killeen et al., 1984; Hajkowicz, 1990). Immel et al. (2001) simulated large-scale TADS launched simultaneously in conjugate auroral zones, which coalesced near the equator. Prolss (1993) indicated that, at low latitudes, the energy dissipation of the two TADs launched in both hemispheres causes an increase in the upper atmosphere temperature and in the gas densities. It should also be mentioned that, during the period of wave-like disturbances, observed on 17 and 19 April, the IMF $B_{z}$ component shows unusually large values (bay and fluctuations). Turunen and Mukunda Rao (1980) (see, also, Rastogi et al., 1978; Galperin et al., 1978) have pointed out that the orientation of the IMF is reflected in the equatorial phenomena.
Recent results of Lee, C. C. et al. (2002, see also Fesen et al., 1989; Bauske and Prolss, 1997) indicate concurrent changes both in $h^{\prime} F / h m F 2$ and foF 2 . However, in the present investigations the $F$-layer height changes $\left(h^{\prime} F\right.$ and $h p F 2$ ) show only concurrent changes with $f o F 2$ on 17 April at PAL and 19 April at SJC. The absence of concurrent height and electron density changes at SJC on 17 April and PAL on 19 April could be related to the effect of absorption or sporadic E blanketing on $h^{\prime} F$ scaling and low time resolution (half hourly) values of $h p F 2$. Figure 5 shows the variations of virtual heights at some fixed reflection frequencies (electron densities), observed during the period 16-20 April at PAL and SJC. The height variations in the $F$-region in Fig. 5 at both PAL and SJC very clearly show wave-like structures during the periods of wave-like structures in $f o F 2$ on both 17 and 19 April.

PAL and SJC are nearly two meridional stations. Therefore, it is easy to identify whether the phenomenon is TAD or $E$-field penetration. In case of TAD a meridional propagation of the disturbance wave with a phase speed of normally $300-600 \mathrm{~m} / \mathrm{s}$ will be observed, whereas with the penetration of the $E$-field, the event must be simultaneous at both stations, since $E$-field penetration occurs simultaneously on a global scale. The increase in AE index could be attributed to 
both substorms or convection enhancement. The latter is the process directly driven by IMF- $B_{z}$ southward without substorm. At mid- and low latitudes, substorms can be identified by positive excursion of $H$-component (duration $1-2 \mathrm{~h}$ ). Figure 2 shows the $H$-component variations observed at a low-latitude station Vassouras and it is seen that on both 17 and 19 April, before the observations of the wave-like disturbances, increases in the AE index are accompanied by shortperiod positive excursions in the $H$-component at Vassouras, indicating launch of TADs due to substorms.

At PAL, the variations of $h^{\prime} F$ on 16 April near 00:00 UT and from 20:00-24:00 UT show large altitudes due to the upward drift associated with the pre-reversal enhancement. In contrast, $h^{\prime} F$ for 20:00-24:00 UT on 17, 18, 19 and 20 April shows that the pre-reversal enhancement was reduced during the storm. The nighttime variations of $h^{\prime} F$ at SJC show strong oscillations in the local post-midnight sector on 18 April after the SSCs on 17 April (11:07 UT) and 18 April (00:32). No such variations in $h^{\prime} F$ were observed at PAL. Fuller-Rowell et al. (1997) have pointed out that, during geomagnetic disturbances, the strongest and most penetrating waves arise on the nightside, where they are hindered least by drag from the low ion densities, and the arrival of the waves to low latitudes may be the cause of the $h^{\prime} F$ changes. After the SSC on 19 April (08:35 UT), the nighttime variations of $h^{\prime} F$, on 19-20 April, show an unusual uplifting of the $F$-region at SJC (about 01:00 UT on 20 April), reaching altitudes of about $300 \mathrm{~km}$ (02:00 UT on 20 April) and then again start uplifting at about 05:30 UT, attaining the maximum height of about $360 \mathrm{~km}$ (07:30 UT on 20 April) before dropping back quickly to about $225 \mathrm{~km}$. The rapid decrease of the $F$-region heights around 09:00 UT (06:00 LT) is mainly a sunrise effect (Abdu, 1997). Comparing the variations in $h^{\prime} F$ at SJC with those at PAL, the variations in $h^{\prime} F$ at PAL after the SSC on 19 April (08:35 UT) show only a small height oscillation, between about 02:00 UT (20 April) and 06:00 UT (20 April), but then there is a very fast uplifting of the $F$ region, attaining a height of $390 \mathrm{~km}$ (about 09:00 UT on 20 April), followed by a quick fall. The sequential $F$-region height rises at $\mathrm{SJC}$, followed at PAL, could be associated with large-scale travelling ionospheric disturbances (Hajkowicz, 1991). During the storm period, no spread- $F$ was observed at SJC. At PAL, the range type spread- $F$ was observed after the fast uplifting of the $F$-layer on 20 April for about an hour close to 09:00 UT. Since the range spread- $F$ is not observed at the low-latitude station SJC, the observed range spread- $F$ at PAL is indicative of strong bottomside spread- $F$ (BSSF) formation near the dip equator (Whalen, 2002).

The variations of virtual heights at some fixed reflection frequencies (electron densities), observed during the period 16-20 April at PAL and SJC, are shown in Fig. 5. The use of multi-frequency ionogram data to study gravity waves is fairly common (e.g. Abdu et al., 1982; MacDougall et al., 1993; Lee et al., 2002). The wave-like disturbances during the daytime on 17 and 19 April at both PAL and SJC, discussed earlier (Figs. 3 and 4), are clearly evident in Fig. 5.

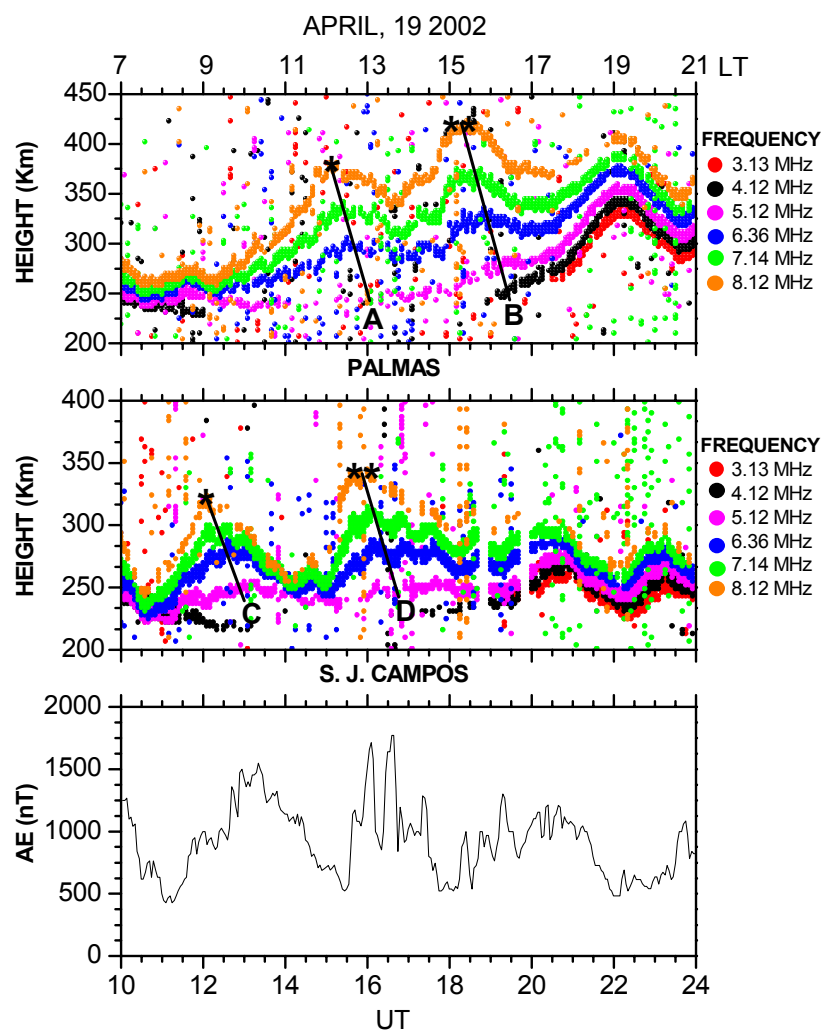

Fig. 6. The virtual height variations for fixed frequencies observed on 19 April 2002, during the period 10:00-24:00 UT (07:0021:00 LT), observed at PAL (top) and SJC (bottom). The transversal lines and the positions marked with asterisks have been used to calculate the vertical phase propagation and horizontal velocities, respectively.

Figure 6 depicts a much shorter subsection of data, revealing details in the iso-frequency plots for the period 10:0024:00 UT (07:00-21:00 LT) on 19 April. Superposed on the two panels of Fig. 6 are oblique lines connecting peaks in the disturbance at different heights. The average vertical (apparent) phase velocity calculated from the 4 trajectories, A, B, $\mathrm{C}$, and $\mathrm{D}$ (changes in virtual height in a certain time interval), shown in Fig. 6, is downward with a value of about $40 \mathrm{~m} / \mathrm{sec}$ and is comparable to about $25 \mathrm{~m} / \mathrm{s}$, a downward speed following a rapid $F$-region rise, reported by Reddy and Nishida (1992). The vertical phase velocities are very similar at the two stations. The average equatorward horizontal velocity computed from the separation of PAL and SJC divided by the time delay between the lines marked $*$ and ** in Fig. 6 is about $157 \mathrm{~m} / \mathrm{sec}$, a TID velocity fairly close to $164 \mathrm{~m} / \mathrm{sec}$ reported by Lee et al. (2002). In general, both these horizontal and vertical velocities are reasonable values for propagating gravity waves, although the horizontal speed is significantly less than expected for large-scale TIDs.

\subsubsection{Observations and the ASPEN-TIMEGCM model re- sults}

The ASPEN-TIMEGCM (Crowley et al., 1999) model results (hourly values), for the variations in $f o F 2$ and $h m F 2$ 
( $F$-region peak height) at PAL and SJC, are presented in Figs. 3 and 4 (orange lines), respectively. The model runs were obtained with appropriate F10.7 solar flux for the day. The size of the auroral oval and the particle fluxes were based on "Hemispheric Power" estimates from the DMSP and NOAA satellites, with values every 15 minutes. The crosscap potential was represented by the Heelis (1982) model driven by the IMF $B_{y}$ component. The cross-cap potential difference was obtained from the Weimer (1996) model driven by solar wind inputs. A comparison of the model results for $f o F 2$, for both PAL and SJC, shows reasonable agreement during the daytime for both quiet and storm conditions. At nighttime (shaded area) the model $f o F 2$ is generally a few MHz below the measured values at both stations, but on the storm days the nighttime foF 2 in the model is much smaller than the measured values.

Figures 3 and 4 depict $h m F 2$ (orange line) for the model superimposed on the $h p F 2$ (black line) measured by the ionosonde at PAL and SJC, respectively. There appears to be reasonable agreement between the variations of $h m F 2$ from the model and the measured $h p F 2$ during the quiet times. However, some discrepancies are observed between the variations of $h m F 2$ from the model and the measured $h p F 2$ during the disturbed conditions at both the stations. It should be pointed out that the discrepancies are more pronounced at SJC. The low-latitude ionosphere is subject to winds, and to electric fields both from the dynamo and penetrating from high latitudes. The model includes winds and dynamo electric fields, but not penetration fields, which may help to explain some of the discrepancies between the model and the observations. In a later paper, a detailed analysis of the magnetic variations in the Brazilian sector may help to identify the magnitude of penetrating $E$-field effects. The discrepancies noted, between the observed and model results, may also indicate that some of the model input parameters need a re-evaluation.

\section{Conclusions}

In this paper we have presented and discussed the simultaneous ionospheric sounding observations from Palmas (PAL), an equatorial location, and São José dos Campos (SJC), located under the equatorial ionospheric anomaly crest, in the Brazilian sector, separated only by about $1460 \mathrm{~km}$, during the period of 16-20 April 2002, which included the multigeomagnetic storm activity between 17-20 April. The important features associated with these observations are summarized below.

1. Soon after the SSCs on 17 and 19 April, the observations at both SJC and PAL exhibited wave-like disturbances both in $f o F 2$ and $F$-region heights during the daytime.

2. At PAL, the variations in $h^{\prime} F$ show considerable reduction in the prereversal enhancement during the full storm period (17-20 April ).
3. The nighttime variations in $h^{\prime} F$, at SJC, show strong oscillations in the local post-midnight sector on 18 April. No such variations were observed at PAL.

4. During the early morning hours of 20 April, the observations at both SJC and PAL show an unusual lifting of the $F$-region. The $F$-region rise in SJC was observed before the event at PAL. Also, only the observations at PAL showed the presence of range type spread- $F$ after the unusual uplifting of the $F$-region.

5. A comparison of the observed $F$-region parameters $h p F 2$ and $f o F 2$, at PAL and SJC, with the ASPENTIMEGCM model results for $h m F 2$ and foF 2 , show reasonable agreement during the quiet period (16 April and a part of 17 April). However, some discrepancies are noted between the observed and model results for both the $F$-region height and peak electron density variations, during the storm period.

Acknowledgements. Thanks are due to Dr. Kazuo Shiokawa for very helpful comments. Thanks are also due Ronaldo Marins de Carvalho, Observatório Nacional, Rio de Janeiro, Brazil, for kindly providing the magnetometer observations carried out at Vassouras, Brazil. The work was partially supported by funds from FAPESP through process number 2002/01631-5.

Topical Editor M. Lester thanks two referees for their help in evaluating this paper.

\section{References}

Abdu, M. A., Major phenomena of the equatorial ionospherethermosphere system under disturbed conditions, J. Atmos. Sol Terr. Phys., 59, 1505-1519, 1997.

Abdu, M. A., Batista, I. S., Kantor, I. J., and Sobral, J. H. A.: Gravity wave induced ionization layers in the night $F$-region over Cachoeira Paulista $\left(22^{\circ} \mathrm{S}, 45^{\circ} \mathrm{S}\right)$, J. Atmos. Terr. Phys., 44, 759767, 1982.

Basu, S., Basu, Su., Groves, K. M., Yeh, H.-C., Su, S.-Y., Rich, F. J., Sultan, P. J., and Keskinen, M. J.: Response of the equatorial ionosphere in the South Atlantic region to the great magnetic storm of 15 July, 2000, Geophys. Res. Lett., 28, 3577-3580, 2001.

Basu, Su., Basu, S., Valladares, C. E., Yeh, H.-C., Su, S.-Y., Mackenzie, E., Sultan, P. J., Aarons, J., Rich, F. J., Doherty, P., Groves, K. M., and Bullet, T. W.: Ionospheric effects of major magnetic storms during the International Space Weather Period of September and October 1999: GPS observations, VHF/UHF scintillations, and in situ density structures at middle and equatorial latitudes, J. Geophys. Res.,106, 30 389-30 413, 2001.

Bauske, R. and Prolss, G. W.: Modeling the ionospheric response to traveling atomospheric disturbances, J. Geophys. Res., 102, 14 555-14 562, 1997.

Blanc, M. and Richmond, A. D.: The ionospheric disturbance dynamo, J. Geophys. Res., 85, 1669-1686, 1980.

Buonsanto, M. J.: Ionospheric storms - A review, Space Sci. Reviews, 88, 563-601, 1999.

Crowley, G., Freitas, C., Ridley, A., Winningham, D., Roble, R. G., and Richmod, A. D.: Next generation space weather specification and forecasting model, proceedings of the ionospheric effects symposium, Alexandria, VA, 34-41, 1999. 
Crowley, G. and McCrea, I. W.: A synoptic study of TIDs observed in the UK during the first WAGS campaign, 10-18 October, 1985, Radio Science, 23, 905-917, 1988.

Crowley, G. and Williams, P. J. S.: Observation of the source and propagation of atmospheric gravity waves, Nature, 328, 231233, 1987.

Crowley, G., Jones, T. B., and Dudeney, J. R.: Comparison of short period TID morphologies in Antarctica during geomagnetically quiet and active intervals, J. Atmos. Terr. Phys., 49, 155, 1987.

Danilov, A. D. and Morozova, L. D.: Ionospheric storms in the $F_{2}$ region. Morphology and Physics (Review), Geomag. Aeron., 25, 593-605, 1985.

Fejer, B. G. and Scherliess, L.: Empirical models of storm time equatorial zonal electic fields, J. Geophys. Res., 102, $24047-$ 24 056, 1997.

Fesen, C. G., Crowley, G., and Roble, R. G.: Ionospheric effects at low latitudes during the March 22, 1979 geomagnetic storm, J. Geophys. Res., 94, 16 961-16968, 1989.

Fuller-Rowell, T. J., Codrescu, M. V., Fejer, B. G., Borer, W., Marcos, F., and Anderson, D. N.: Dynamics of the low-latitude thermosphere: queit and disturbed conditions, J. Atmos. Sol. Terr. Phys., 59, 1533-1540, 1997.

Galperin, Yu. I., Ponomarev, V. N., and Zosimova, A. G.: Equatorial ionospheric anomaly and interplanetary magnetic field, J. Geophys. Res., 83, 4265-4272, 1978.

Grant, I. F., MacDougall, J. W., Ruohoniemi, J. M., Bristow, W. A., Sofko, G. J., Koehler, J. A., Danskin, D., and Andre, D.: Comparison of plasma flow velocities determined by the ionosonde Doppler drift technique, SuperDARN radars, and patch motion, Radio Sci., 30, 1537-1549, 1995.

Hajkowicz, L. A.: A global study of large scale traveling ionospheric disturbances (TIDS) following a step-like onset of auroral substorms in both hemispheres, Planet. Space. Sci., 38, 913923, 1990.

Hajkowicz, L. A.: Auroral electrojet effect on the global occurrence pattern of large scale travelling ionospheric disturbances, Planet. Space Sci., 39, 1139-1196, 1991.

Heelis, R. A., Lowell, J. K., and Spiro, R. W.: A model of the high latitude ionospheric convection pattern, J. Geophys. Res., 87, 6339-6345, 1982.

Immel, T. J., Crowley, G., and Craven, J. D.: Dayside enhancements of thermospheric $\mathrm{O} / \mathrm{N} 2$ following a magnetic storm onset, J. Geophy. Res., 106, 15 471-15 488, 2001.

Killeen, T. L., Hays, P. B., Carignan, G. R., Heelis, R. A., Hanson, W. B., Spencer, N. W., and Brace, L. H.: Ion-neutral coupling in the high-latitude $\mathrm{F}$ region: Evaluation of ion heating terms from Dynamic Explorer 2, J. Geophys. Res., 89, 7495-7508, 1984.

Lee, C.-C., Liu, J.-Y., Reinisch, B. W., Lee, Y.-P., Liu, L.: The propagation of traveling atmospheric disturbances observed during the 6-7 April 2000 ionospheric storm, Geophys. Res. Lett., 29, 10.1029/2001GL013516, 2002.

Lee, J. J., Min, K. W., Kim, V. P., Hegai, V. V., Oyama, K.-I., Rich, F. J., and Kim, J.: Large density depletions in the nighttime upper ionosphere during the magnetic storm of 15 July, 2000, Geophys. Res. Lett., 29, 10.1029/2001GL013991, 2002.

MacDougall, J. W., Halland, G. E., and Hayashi, K.: F-region gravity waves in the central polar cap, J. Geophys. Res., 102, 14 513$14530,1997$.

Prolss, G. W.: Common origin of positive ionospheric storms at middle latitudes and the geomagnetic activity effect at low latitudes, J. Geophys. Res., 98, 5981-5991, 1993.
Prolss, G. W. and Najita, K.: Magnetic storm associated changes in the electron content at low latitudes, J. Atmos. Terr. Phys., 37, 635-643, 1975.

Rastogi, R. G., Woodman, R. F., and Hedgecock, P. C.: Correlated changes in the equatorial electrojet and in the interplanetary magnetic field during a geomagnetic storm, J. Atmos. Terr. Phys., 40, 867-869, 1978.

Reddy, C. A. and Nishida, A.: Magnetospheric substorms and nighttime height changes of the $\mathrm{F} 2$ region at middle and low latitudes, J. Geophys. Res., 97, 3039-3061, 1992.

Rice, D. D., Hunsucker, R. D., Lanzerotti, L. J., Crowley, G., Williams, P. J. S., J. D. Craven, J. D. and Frank, L.: An observation of atmospheric gravity wave cause and effect during the October 1985 WAGS campaign, Radio Science, 23, 919-930, 1988.

Roble, R. G. and Ridley, A.: Thermosphere-IonosphereMesosphere-Electro Dynamics General Circulation Model (TIME-GCM): Equinox solar cycle minimum simulations (300500 km), Geophys. Res. Lett., 22, 417-420, 1994.

Sastri, J. H., Niranjan, K., and Subbarao, K. S. V., Response of the equatorial ionosphere in the Indian (midnight) sector to the severe magnetic storm of 15 July, 2000, Geophys. Res. Lett., 29, 10.1029/2002GL015133, 2002.

Scherliess, L. and Fejer, B. G.: Storm time dependence of equatorial disturbance dynamo zonal electric fields, J. Geophys. Res., 102, 24 037-24 046, 1997.

Schunk, R. W. and Sojka, J. J.: Ionosphere-thermosphere space weather issues, J. Atmos. Terr. Phys., 58, 1527-1574, 1996.

Senior, C. and Blanc, M.: On the control of magnetospheric convection by the spatial distribution of ionospheric conductivities, J. Geophys. Res., 89, 261-284, 1984.

Sobral, J. H. A., Abdu, M. A., González, W. D., Tsurutani, B. T., Batista, I. S., and Clua de González, A. L.: Effects of intense storms and substorms on the equatorial ionosphere/thermosphere system in the American sector from ground-based and satellite data, J. Geophys. Res., 102, 14 302-14313, 1997.

Spiro, R. W., Wolf, R. A., and Fejer, B. G.: Penetration of highlatitude-electric-field effects to low latidudes during SUNDIAL 1984, Ann. Geophys. 6, 39-50, 1988.

Sridharan, R., Taori, A., Chakrabarty, D., Chandra, H., Sharma, S., Narayanan, R., and Modi, N. K.: Effects of 6 January 1997 space weather related processes in the low latitude thermosphereionosphere system, J. Atmos. Sol. Terr. Phys., 61, 1001-1005, 1999.

Tanaka, T.: The worldwide distribution of positive ionospheric storms, J. Atmos. Terr. Phys., 41, 103-110, 1979.

Turunen, T. and Mukunda Rao, M.: Examples of the influence of strong magnetic storms on the equatorial $F$-layer, J. Atmos. Terr. Phys., 42, 323-330, 1980.

Weimer, D. R.: A flexible, IMF dependent model of high-latitude electric potentials having "space weather" applications, Geophys. Res. Lett., 23, 2549-2552, 1996.

Whalen, J. A.: Dependence of quatorial bubbles and bottomside spread $\mathrm{F}$ on season, magnetic activity, and $\mathrm{E} \times \mathrm{B}$ drift velocity during solar maximum, J. Geophys. Res., 107, A2, 10.1029/2001JA000039, 2002.

World Data Center A for Solar-Terrestrial Physics: U.R.S.I. handbook of ionogram interpretation and reduction, edited by Piggot, W. R. and Rawer, K., report UAG-23, 2nd edition, 21, 1972. 